\title{
Acidic Glycosaminoglycans and Gangliosides in the Brains from Four Patients with Genetic Mucopolysaccharidosis
}

\author{
Tomoyasu Ikeno, Ryoji Minami, Satoshi Tsugawa* and \\ ToOru NakaO \\ Department of Pediatrics, Sapporo Medical College, Sapporo \\ 060 and *Otaru National Sanatorium, Otaru 047
}

\begin{abstract}
Ikeno, T., Minami, R., Tsugawa, S. and Nakao, T. Acidic Glycosaminoglycans and Gangliosides in the Brains from Four Patients with Genetic Mucopolysaccharidosis. Tohoku J. exp. Med., 1982, 137 (3), 253-260 — Acidic glycosaminoglycans (GAGs) and gangliosides were analyzed in the brains from control fetuses, fetal Hurler syndrome, control children and three patients affected by genetic mucopolysaccharidosis (Hurler, Hunter and Morquio syndromes). GAGs contents in the brains from patients with Hurler and Hunter syndromes were approximately 1.5-3.0-fold greater as compared with those from controls, and most of the GAGs were much more degraded than those from controls. Dermatan sulfate (DS), which was not identified in the control brains, comprised about $20-40 \%$ of the total GAGs. On the other hand, GAGs content and molecular weight distribution in the brain from the patient affected by Morquio syndrome were similar to those in the control brains. GAGs content in the brain from fetal Hurler syndrome was also 2.0-fold greater and DS, which was not detected in the control fetal brains, comprised $1.6 \%$ of the total GAGs. However, the molecular weight distribution of the GAGs was similar to those of the control fetal brains. The total amount of the brain gangliosides in all patients assayed here was similar to those in the control brains. However, a greater amount of $\mathrm{G}_{\mathrm{M}_{1}}$ - and $\mathrm{G}_{\mathrm{M}_{2}}$-gangliosides was observed in the brains from patients with Hurler and Hunter syndromes. - acidic glycosaminoglycans; gangliosides; mucopolysaccharidosis.
\end{abstract}

In genetic mucopolysaccharidosis (MPS), deficiencies of specific lysosomal enzymes required for degradation of acidic glycosaminoglycans (GAGs) have been found to be responsible for their basic defects. However, systematic investigations of the GAGs in various organs, especially the brains from those patients are scanty. We have previously analyzed GAGs accumulated in the livers from patients with Hurler, Hunter and Morquio syndromes (Minami et al. 1979, 1981). In this paper, we have extended our studies on brain GAGs and gangliosides from four patients with MPS (Hurler, fetal Hurler, Hunter and Morquio syndromes).

\section{Materials and Methods}

The brain tissues were obtained from three control children, two control fetuses and four patients with MPS (Hurler, fetal Hurler, Hunter and Morquio syndromes). The

Received for publication, August 11, 1981. 
diagnosis in all the patients has been determined by typical clinical pictures and enzymatic findings.

Brain GAGs were isolated by a procedure described previously (Brunngraber et al. 1971; Minami et al. 1979, 1981). The absence of GAGs in water and $0.25 \mathrm{M} \mathrm{NaCl}$ fractions was confirmed by electrophoresis. Finally, 4.0 M NaCl fraction was analyzed for brain GAGs. The molecular weight distribution of GAGs was determined by the method previously described (Constantopoulos et al. 1976). The enzymatic digestion of the GAGs was performed by the method previously described (Saito et al. 1968; Ohya and Kaneko 1970).

High performance liquid chromatography (HPLC) was used for determination of relative proportions of chondroitin-4-sulfate (C-4S), chondroitin-6-sulfate (C-6S), dermatan sulfate (DS), hyaluronic acid (HA) and chondroitin. The apparatus used was Model 638 (Hitachi Co., Ltd.) solvent delivery system equipped with Model UV-8 Photometer (232 nm) (Toyosoda Co., Ltd.). Peak heights, peak area and retention times were measured by Chromatopac (Shimadzu Co., Ltd.). Partisil 10-pac Column (Whatman Laboratories Clifton, N.J.) was employed. $\quad 10.0 \mu \mathrm{l}$ of each enzymatically digested solution was chromatographed at $2 \mathrm{ml} / \mathrm{min}$ with a ternary solvent system of acetonitrile, methanol and $0.5 \mathrm{~mole} / \mathrm{liter}$ ammonium formate buffer $(\mathrm{pH} 4.8)(60: 20: 20 \mathrm{v} / \mathrm{v} / \mathrm{v})$. Separations were carried out isocratically at room temperature (Lee and Tieckelmann 1979; Lee et al. 1980). Heparan sulfate (HS) was estimated by using GAGs undigested with chondroitinase ABC and streptomyces hyaluronidase.

Uronic acid was determined by the carbazole reaction (Dische 1947), and orcinol reaction (Brown 1946), hexosamine by the method of Boas (1953), hexose by the anthrone method (Roe 1955), total sulfate by the method of Dodgson and Price (1962), N-sulfate by the method of Lagunoff and Warren (1962), sialic acid by the Warren assay (1959) and quantitative estimation of glucosamine/galactosamine by amino-auto-analyzer Model KLA5 (Hitachi Co., Ltd.).

The extraction and separation of brain gangliosides were carried out by the method of Folch et al. (1957). Thin-layer chromatography on silica gel G (Merk) was used to quantify individual gangliosides. The solvent system used was chloroform, methanol and $2.5 \mathrm{~N}$ ammonia $(60: 40: 9 \mathrm{v} / \mathrm{v} / \mathrm{v})$ (Suzuki 1964). Resorcinol reagent was used for visualization of gangliosides and determination of $\mathrm{N}$-acetylneuraminic acid (NANA) content (Svennerholm 1956).

\section{Results}

The results of analysis of GAGs are summarized in Table 1. There was 2.7fold increase in the GAGs content (as uronic acid) of brain from Hurler syndrome and 2.2-fold increase in Hunter syndrome as compared with those of the control brains. The total amount of GAGs in the brain from Morquio syndrome was at normal level. The total amount of GAGs in the fetal Hurler syndrome was about 2.0-fold greater as compared with those of the control fetal brains. N-Sulfate content in the affected fetal brain was $0.04 \mathrm{mg}$, and the content in the control fetal brains was not identified.

By digestion with chondroitinase $\mathrm{AC}, \Delta \mathrm{D}_{\mathrm{i}}-4 \mathrm{~S}$ was produced only from $\mathrm{C}-4 \mathrm{~S}$, whereas it was produced from $\mathrm{C}-4 \mathrm{~S}$ and $\mathrm{DS}$ by digestion with chondroitinase $\mathrm{ABC}$. In the control brain, the amount of $\Delta \mathrm{D}_{\mathrm{i}}-4 \mathrm{~S}$ obtained by digestion with chondroitinase $\mathrm{ABC}$ was the same as that obtained by digestion with chondroitinase AC. But in Hunter syndrome, the amount of $\Delta \mathrm{D}_{\mathrm{i}}-4 \mathrm{~S}$ obtained by digestion with chondroitinase $\mathrm{ABC}$ was always larger than that obtained by digestion with chondroitinase $\mathrm{AC}$ (Fig. 1). 


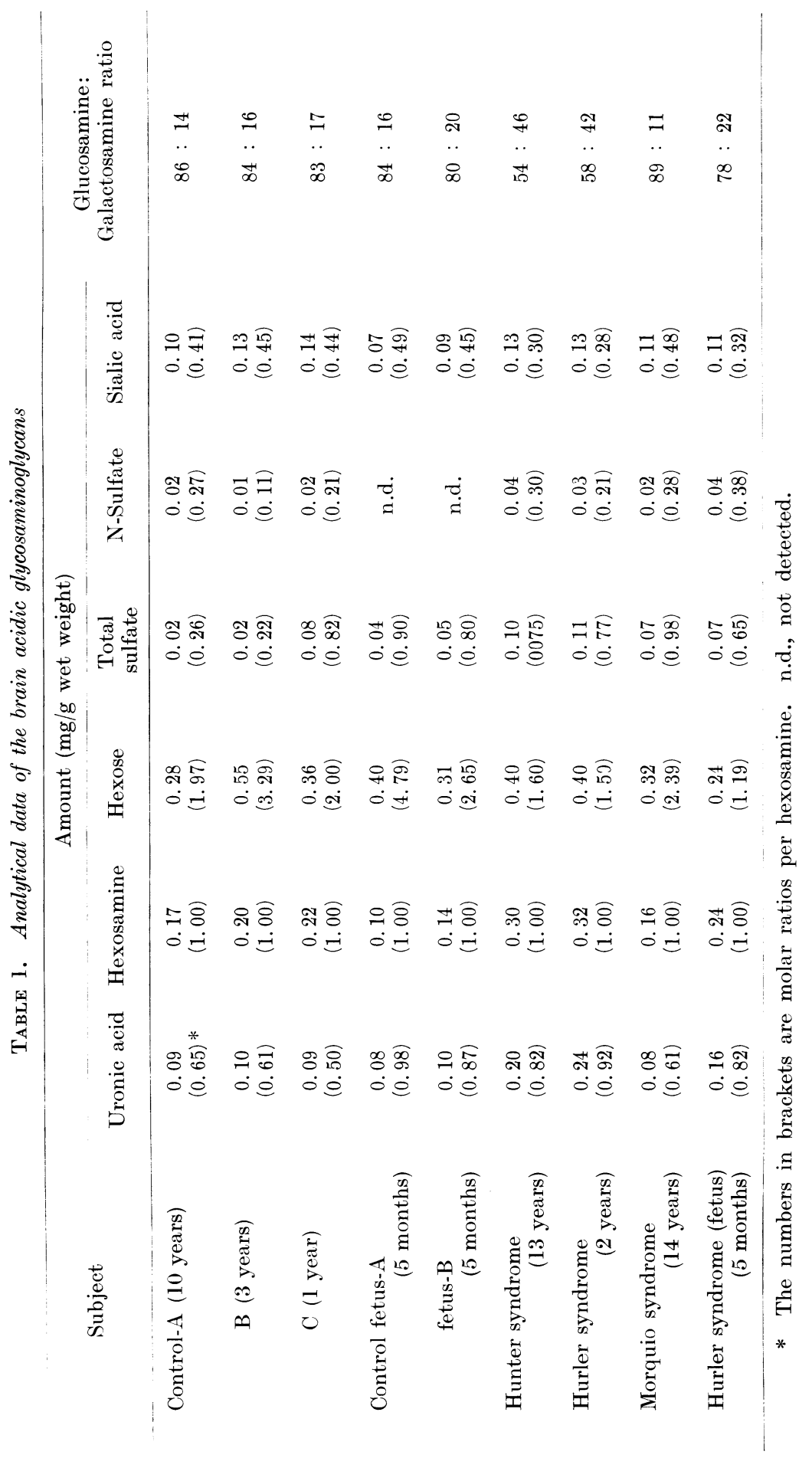



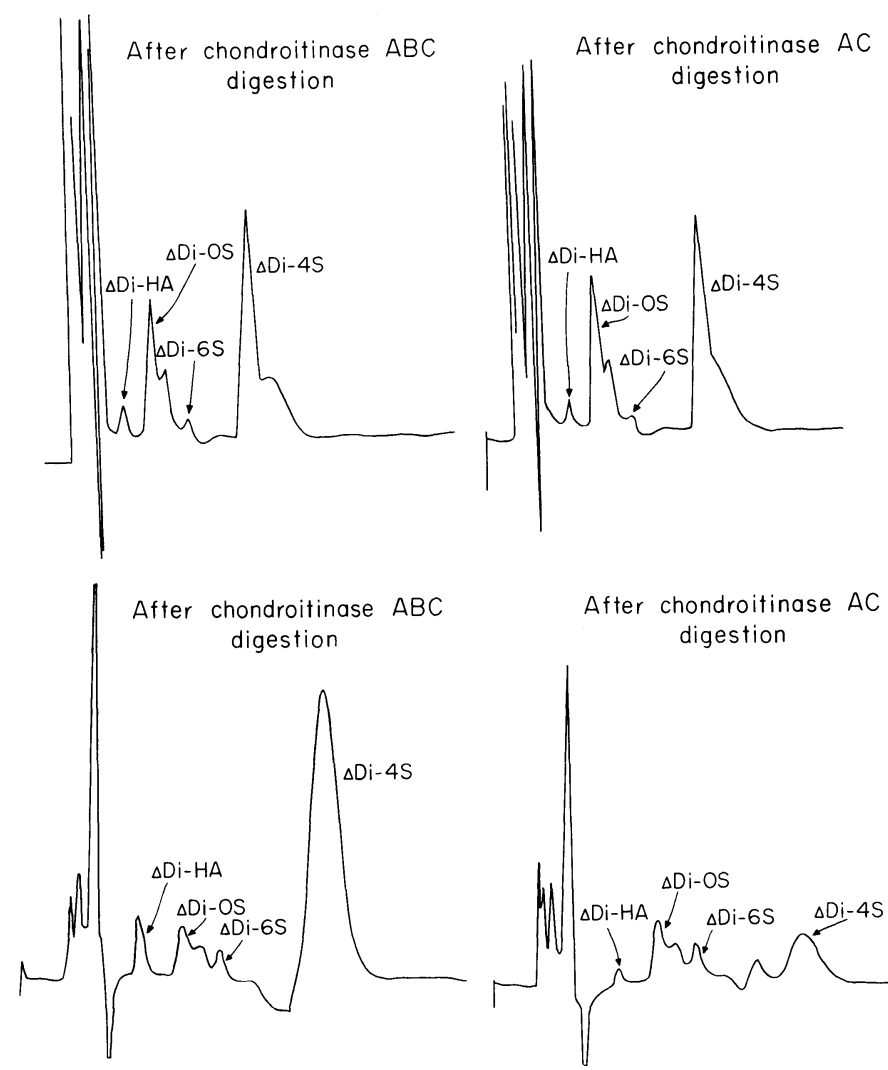

After chondroitinase $A C$ digestion

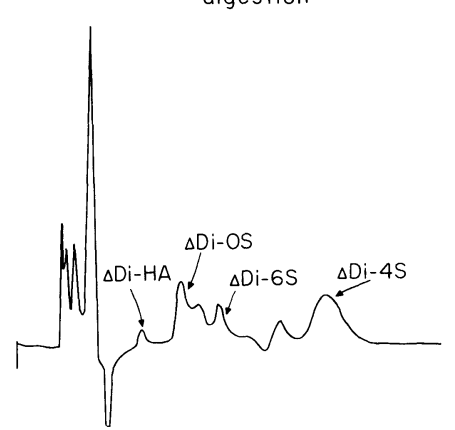

Fig. 1. High performance liquid chromatography of enzymatic degradation products of GAGs in the brains from a control child (upper panel) and a child with Hunter syndrome (lower panel).

TABLE 2. Composition of the brain acidic glycosaminoglycans (\% of total hexosamine)

\begin{tabular}{|c|c|c|c|c|c|c|}
\hline Subject & $\begin{array}{l}\text { Chondroitin } \\
\text { 4-sulfate }\end{array}$ & $\begin{array}{l}\text { Dermatan } \\
\text { sulfate }\end{array}$ & $\begin{array}{c}\text { Chondroitin } \\
6 \text {-sulfate }\end{array}$ & Chondroitin & $\begin{array}{l}\text { Hyaluronic } \\
\text { acid }\end{array}$ & $\begin{array}{l}\text { Heparan } \\
\text { sulfate }\end{array}$ \\
\hline Control-A (10 years) & 9.4 & n.d. & 4.2 & 12.7 & 22.8 & 50.9 \\
\hline B (3 years) & 12.4 & n.d. & 5.4 & 6.8 & 27.2 & 48.2 \\
\hline C (1 year) & 10.5 & n.d. & 3.0 & 5.3 & 9.9 & 71.3 \\
\hline $\begin{array}{l}\text { Control fetus-A } \\
\qquad \text { (5 months) }\end{array}$ & 9.8 & n.d. & 1.3 & 6.1 & 14.2 & 68.6 \\
\hline $\begin{array}{l}\text { fetus-B } \\
\text { (5 months) }\end{array}$ & 11.7 & n.d. & 6.8 & 6.7 & 15.9 & 58.9 \\
\hline $\begin{array}{l}\text { Hunter syndrome } \\
\text { (13 years) }\end{array}$ & 7.9 & 33.9 & 3.1 & 6.3 & 22.3 & 26.5 \\
\hline $\begin{array}{l}\text { Hurler syndrome } \\
\text { (2 years) }\end{array}$ & 4.9 & 17.7 & 3.9 & 8.6 & 10.1 & 54.8 \\
\hline $\begin{array}{l}\text { Morquio syndrome } \\
\text { (14 years) }\end{array}$ & 14.2 & n.d. & 7.3 & 6.9 & 25.5 & 46.1 \\
\hline $\begin{array}{l}\text { Fetal Hurler } \\
\text { syndrome } \\
\qquad(5 \text { months })\end{array}$ & 4.6 & 1.6 & 3.1 & 4.9 & 18.0 & 67.8 \\
\hline
\end{tabular}
n.d., not detected. 
The composition of brain GAGs of the controls and patients is shown in Table 2. DS comprised $17.7 \%$ of the total GAGs in Hurler syndrome, $33.9 \%$ in Hunter syndrome and $1.6 \%$ in fetal Hurler syndrome, while no DS was detected in the control brains. In Morquio syndrome, neither DS nor keratan sulfate (KS), which was identified in the liver (Minami et al. 1979), was detected in the brain. With regard to other GAGs components, no significant difference was noted between the controls and three patients.
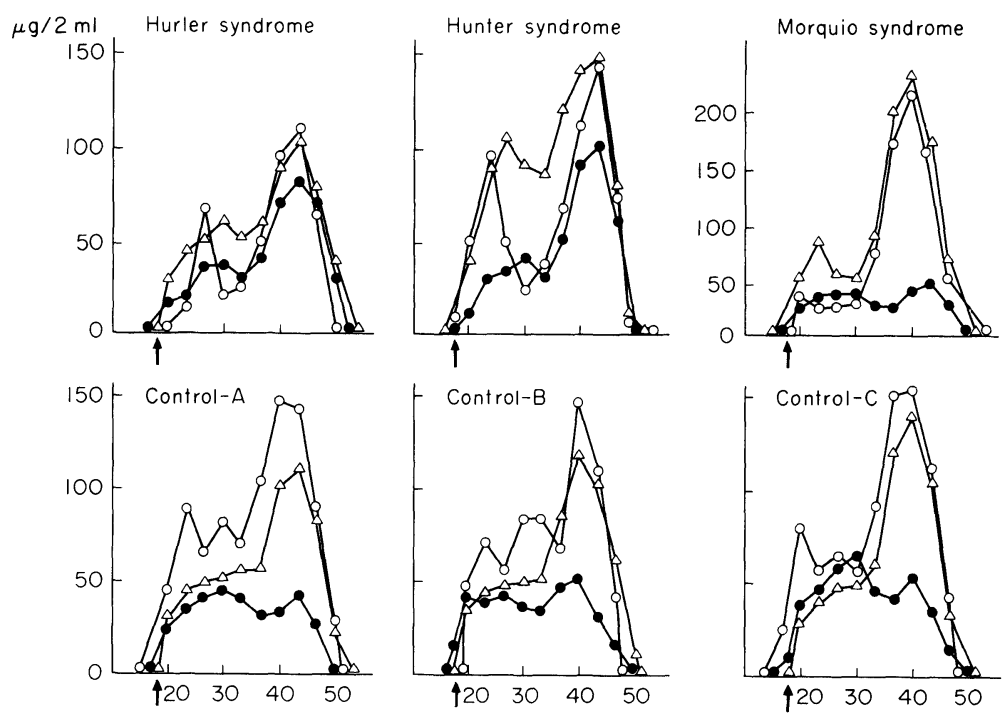

Eluate volume $(\mathrm{ml})$

Fig. 2. Elution patterns in Sephadex G-200 gel filtration for GAGs from the brains of the control children and patients affected by genetic mucopolysaccharidcsis (Hurler, Hunter and Morquio syndromes).

•, uronic acid (carbazole); $\Delta$, uronic acid (orcinol); o, hexose; 1 , blue dextran.
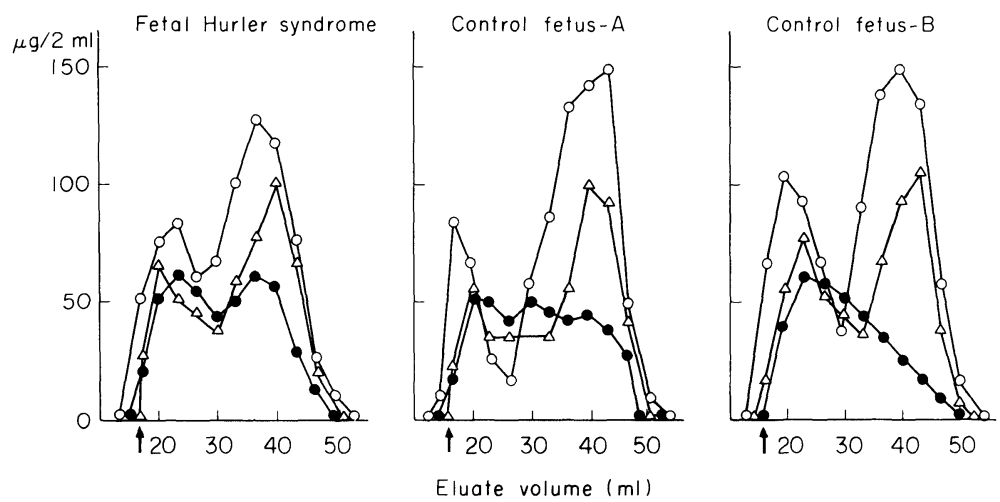

Fig. 3. Elution patterns in Sephadex G-200 gel filtration for GAGs from the brains of the control fetuses and fetal Hurler syndrome.

•, uronic acid (carbazole); $\Delta$, uronic acid (orcinol); o, hexose.; $\mathbf{\uparrow}$, blue dextran. 
Figs. 2 and 3 show the molecular weight distribution of the brain GAGs in the controls and the patients. The elution curve of Sephadex G-200 gel filtration consisted of two peaks in the controls. The first peak represented large molecular weight GAGs and second peak small ones. In Hurler and Hunter syndromes, the small molecular weight GAGs were larger in amount than the large molecular weight GAGs. However, the elution curves in the brains of Morquio and fetal Hurler syndromes were similar to those in respective control brains.

The total amount of the brain gangliosides in all the patients was similar to that in the controls (Table 3). However, a greater amount of $\mathrm{G}_{\mathrm{M}^{-}}$and $\mathrm{G}_{\mathrm{M} 3}$-gangliosides was observed in the brain from Hurler and Hunter syndromes (Fig. 4). There were

TABLE 3. Composition of gangliosides in the brain

\begin{tabular}{|c|c|c|c|c|c|c|c|}
\hline \multirow{2}{*}{ Subject } & \multirow{2}{*}{$\begin{array}{c}\text { NANA } \\
(\mathrm{mg} / \mathrm{g} \text { wet weight })\end{array}$} & \multicolumn{6}{|c|}{ Distribution of NANA (\%) } \\
\hline & & $\mathrm{G}_{\mathrm{T} 1}$ & $\mathrm{G}_{\mathrm{D} 1 \mathrm{~b}}$ & $\mathrm{G}_{\mathrm{D} 1 \mathrm{a}}$ & $\mathrm{G}_{\mathrm{M} 1}$ & $\mathrm{G}_{\mathrm{M} 2}$ & $\mathrm{G}_{\mathrm{M} 3}$ \\
\hline Control-A (10-years) & 0.66 & 14.5 & 15.4 & 41.5 & 22.5 & 3.8 & 2.3 \\
\hline B (3 years) & 0.69 & 11.6 & 15.6 & 39.2 & 27.2 & 3.8 & 2.6 \\
\hline C (1 year) & 0.64 & 11.5 & 11.5 & 40.6 & 29.2 & 4.1 & 3.1 \\
\hline $\begin{array}{l}\text { Control fetus-A } \\
\qquad \text { (5 months) }\end{array}$ & 0.31 & 14.2 & 9.5 & 53.6 & 14.9 & 5.4 & 2.4 \\
\hline $\begin{array}{l}\text { fetus-B } \\
\qquad(5 \text { months })\end{array}$ & 0.31 & 15.4 & 10.8 & 48.9 & 17.5 & 5.7 & 1.7 \\
\hline $\begin{array}{l}\text { Hunter syndrome } \\
\text { (13 years) }\end{array}$ & 0.51 & 15.4 & 21.5 & 31.9 & 18.2 & 5.8 & 7.2 \\
\hline $\begin{array}{l}\text { Hurler syndrome } \\
\qquad(2 \text { years })\end{array}$ & 0.75 & 9.5 & 14.6 & 33.1 & 23.3 & 7.5 & 12.0 \\
\hline $\begin{array}{l}\text { Morquio syndrome } \\
\text { (14 years) }\end{array}$ & 0.65 & 13.2 & 15.2 & 37.7 & 27.2 & 3.7 & 3.0 \\
\hline $\begin{array}{l}\text { Fetal Hurler syndrome } \\
\text { ( } 5 \text { months })\end{array}$ & 0.36 & 18.5 & 11.9 & 47.1 & 15.5 & 5.7 & 1.3 \\
\hline
\end{tabular}

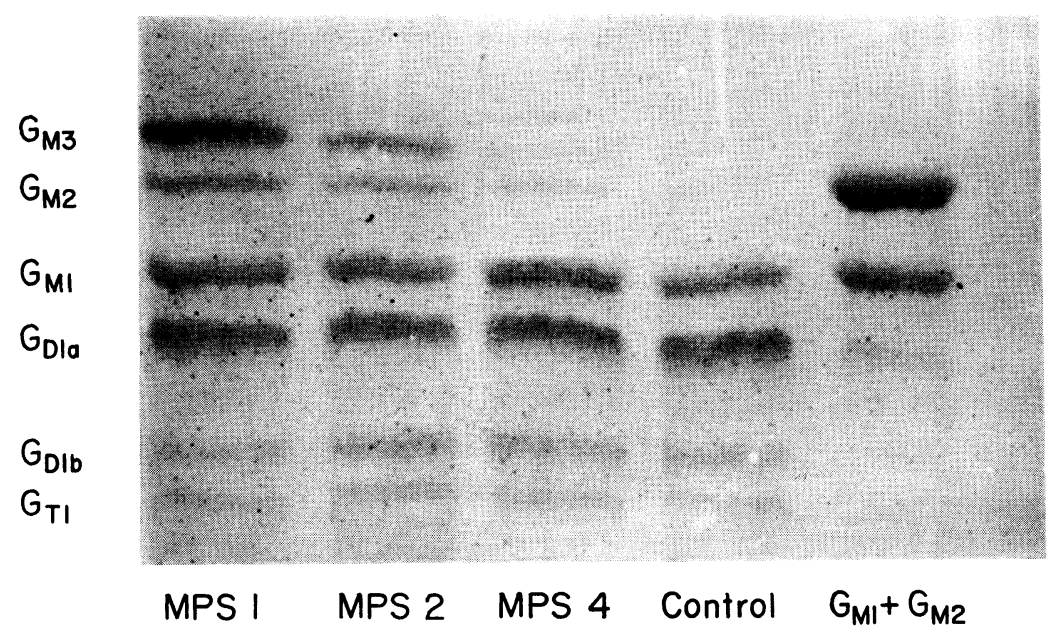

Fig. 4. Thin-layer chromatogram of gangliosides in the brains from patients affected by genetic mucopolysaccharidosis. 
1.5-fold increase in $\mathrm{G}_{\mathrm{M} 2}$-ganglioside and 2.7-fold increase in $\mathrm{G}_{\mathrm{M} 3}$-ganglioside in Hunter syndrome, and 2.0-fold increase and 4.0-fold increase in Hurler syndrome, respectively.

\section{Discussion}

In order to determine relative proportions of GAGs, unsaturated disaccharides digested with chondroitinase are usually determined by paper chromatography (Saito et al. 1968). However, the method has several disadvantages such as time consuming and limited sensitivity. On the other hand, the HPLC method used in our experiments permits a more rapid, sensitive and simple procedure than the method hitherto used.

GAGs contents in the brains from fetal Hurler, Hurler and Hunter syndromes were approximately 1.5-3.0-fold greater than controls, and DS comprised $1.6 \%$ of the total GAGs in fetal Hurler syndrome, $17.7 \%$ in Hurler syndrome and $33.9 \%$ in Hunter syndrome. From these data, it was suggested that GAGs were already accumulated at the fetal period and increased with aging. On the other hand, GAGs content and molecular weight distribution in the brain affected by Morquio syndrome were similar to those in the controls and, moreover, KS which was identified in the liver (Minami et al. 1979), was not detected in the brain. Therefore, unlike other MPS, the fact that patients with Morquio syndrome have usually no mental retardation could be explained.

Abnormal distribution of the brain gangliosides such as increases of $\mathrm{G}_{\mathrm{M}^{-}}, \mathrm{G}_{\mathrm{M}^{-}}$, $\mathrm{G}_{\mathrm{M} 3}$-gangliosides has been observed in the brain from patients with Hurler, Hunter and Sanfilippo syndromes (Constantopoulos and Dekaban 1978; Constantopoulos et al. 1978; Dacremont et al. 1974). However, the pathogenetic processes leading to this phenomenon are still obscure. Constantopoulos and Dekaban (1978) suggested that the drastic changes in content, composition, structure and molecular size of the brain GAGs might affect the metabolism of gangliosides, because no increase of $\mathrm{G}_{\mathrm{M}^{-}}$or $\mathrm{G}_{\mathrm{M} 3}$-gangliosides was observed in Scheie syndrome without marked changes of brain GAGs. In our studies, the increases of $\mathrm{G}_{\mathrm{M}^{-}}$and

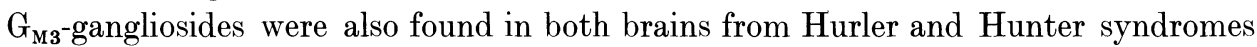
containing excessive amounts of degraded GAGs. Therefore, the speculation of Constantopoulos and Dekaban (1978) could be supported from the results of our experiments. On the other hand, GAGs accumulated in the brain from fetal Hurler syndrome were still undegraded in contrast to those in Hurler syndrome at childhood and the abnormal pattern of gangliosides was not observed either. It is therefore tempting to speculate that catabolism of brain gangliosides may not be affected by the accumulation of large molecular GAGs, but may be affected by the accumulation of degraded GAGs in MPS.

\section{References}

1) Boas, N.F. (1953) Method for the determinations of hexosamine in tissues. J. biol. Chem., 204, 553-563.

2) Brown, A.H. (1946) Determination of pentose in the presence of large quantities of glucose. Arch. Biochem., 11, 269-278. 
3) Brunngraber, E.G.. Brown, R.D. \& Hof, H. (1971) Determination of gangliosides, glycoproteins and glycosaminoglycans in brain tissue. Clin. chim. Acta, 32, 159-170.

4) Constantopoulos, G. \& Dekaban, A.S. (1978) Neurochemistry of the mucopolysaccharidosis: Brain and lysosomal enzymes in patients with four types of mucopolysaccharidosis and in normal controls. J. Neurochem., 30, 965-973.

5) Constantopoulos, G., McComb, R.D. \& Dekaban, A.S. (1976) Neurochemistry of the mucopolysaccharidosis: Brain glycosaminoglycans in normals and four types of mucopolysaccharidosis. J. Neurochem., 26, 901-908.

6) Constantopoulos, G., Eiben, R.M. \& Schafter, I.A. (1978) Neurochemistry of the mucopolysaccharidosis: Brain glycosaminoglycans, lipids and lysosomal enzymes in mucopolysaccharidosis type III B. J. Neurochem., 31, 1215-1222.

7) Dacremont, G., Kint, J.A. \& Cocquyt, G. (1974) Brain sphingolipids in I-cell (mucolipidosis II). J. Neurochem., 22, 599-602.

8) Dische, Z. (1947) A new specific color reaction of hexuronic acids. J. biol. Chem., 167, 189-198.

9) Dodgson, K.S. \& Price, R.G. (1962) A note on the determination of the ester sulphate content of sulphated polysaccharides. Biochem. J., 84, 106-110.

10) Folch, J., Lees, M. \& Sloane-Stanley, G.H. (1957) A simple method for the isolation and purification of total lipids from animal tissues. J. biol. Chem., 226, 497-509.

11) Lagunoff, D. \& Warren, G. (1962) Determination of 2-deoxy-2-suloamino-hexose content of mucopolysaccharides. Arch. Biochem. Biophys., 99, 396-440.

12) Lee, G.J.L. \& Tieckelmann, H. (1979) High performance liquid chromatographic determinations of disaccharides resulting from enzymatic degradation of isometric chondroitin sulfates. Analyt. Biochem., 94, 231-236.

13) Lee, G.J.L., Evans, J.E., Tieckelmann, H., Dulaney, J.T. \& Naylor, E.W. (1980) Enzymatic studies of urinary isometric chondroitin sulfates from patients with mucopolysaccharidoses. The application of high performance liquid chromatography. Clin. chim. Acta, 104, 65-75.

14) Minami, R., Abo, K., Kudoh, T., Tsugawa, S., Oyanagi, K. \& Nakao, T. (1979) Identification of keratan sulfate in liver affected by Morquio syndrome. Clin. chim. Acta, 93, 207-213.

15) Minami, R., Abo, K., Tsugawa, S., Oyanagi, K. \& Nakao, T. (1981) Acidic glycosaminoglycans in liver from five patients with mucopolysaccharidosis and mucolipidosis. Tohoku J. exp. Med., 134, 215-220.

16) Ohya, T. \& Kaneko, Y. (1970) Novel hyaluronidase from streptomyces. Biochim. biophy. Acta, 198, 607-609.

17) Roe, J.H. (1955) The determination of sugar in blood and spinal fluid with anthrone reagent. J. biol. Chem., 212, 335-343.

18) Saito, H., Yamagata, T. \& Suzuki, S. (1968) Enzymatic methods for the determination of quantities of isometric chondroitin sulfates. J. biol. Chem., 243, 1536-1542.

19) Suzuki, K. (1964) A simple and accurate micromethod for quantitative determination of ganglioside patterns. Life Sci., 3, 1227-1233.

20) Svennerholm, L. (1956) The determination of hexosamine with special reference to nervous tissue. Acta soc. med. upsl., 61, 287-306.

21) Warren, L. (1959) The thiobarbituric acid assay of sialic acids. J. biol. Chem., 234, 1971-1975. 